\title{
As políticas de planejamento educacional no Brasil: tensões, avanços e desafios
}

\begin{abstract}
Apresentamos este número da RBPAE em uma emblemática conjuntura social e política cindida por duas forças antagônicas: de um lado os parlamentares dos partidos políticos que fazem oposição ao governo, o vice-presidente da República e o presidente da Câmara dos Deputados, que, com o apoio dos grandes meios de comunicação, da Federação das Indústrias do Estado de São Paulo (FIESP) e de grande parte da elite econômica coloca em curso um processo de impeachment contra a presidente Dilma Rousseff. De outro lado, posicionamse forças progressistas, que fazem resistência a esse processo, formadas por parlamentares dos partidos que apoiam o governo, movimentos organizados de trabalhadores, estudantes, juristas, artistas, intelectuais, povos indígenas, do campo, da comunidade LGBT, além de grande parte da imprensa internacional, organismos internacionais como a OEA e a Unasul ${ }^{1}$ que consideram o impeachment grave ameaça à democracia e ao Estado de Direito no Brasil.

A abertura do processo de impeachment foi admitida pela Câmara dos Deputados sob o argumento de que a presidente teria cometido crime de responsabilidade ${ }^{2}$, que, somado à baixa popularidade da governante, contribuiu para o agravamento das crises política e econômica. Esse cenário de instabilidade
\end{abstract}

1 De acordo com Ernesto Samper, Secretário-geral da Unasul, “Aceitar que um mandatário possa ser tirado do cargo por supostas falhas em atos de caráter administrativo levaria a uma perigosa criminalização do exercício do governo por razões de índole simplesmente política". Disponível em: https://www.nexojornal. com.br/expresso/2016/04/17/Como-OEA-e-Unasul-veem-o-impeachment.-E-qual-o-risco-de-Temer$\mathrm{n} \% \mathrm{C} 3 \% \mathrm{~A} 3 \mathrm{O}-$-ser-reconhecido.

2 Os crimes de responsabilidades são infrações político-administrativas, definidas em lei especial federal, que poderão ser cometidas no desempenho da função pública e que poderão resultar no impedimento para o exercício da função pública (impeachment). A competência para processar e julgar o Presidente da República nos crimes de responsabilidade é do Senado Federal (art. 52, I, CF), após autorização da Câmara dos Deputados, por dois terços (2/3) dos seus membros (art. 51, I,CF). Disponível em: http://www.stf.jus.br/ portal/constituicao/artigobd.asp. A presidente é acusada de assinar decretos para executar "pedaladas fiscais", considerados pelos defensores do impeachment um crime de responsabilidade. Entretanto, há controvérsias sobre essa interpretação: para o professor emérito da USP, Dalmo Dallari, “os decretos assinados por Dilma não são crimes orçamentários, apenas medidas contábeis administrativas: Não foram gastos ilegais, para beneficiar a própria Dilma, amigos ou terceiros. Nas 'pedaladas' apenas se mudou a data de transferência de recursos a bancos. Ninguém se apoderou do dinheiro público, que continuou com uso público. As "pedaladas" não se enquadram em nenhuma das hipóteses previstas em lei". O jurista Fabio Konder Comparato, professor da USP, também contesta a existência de crime de responsabilidade: "Quando a União deixa de fazer repasses para certas entidades, para que elas usem recursos delas e recebam depois, dizer que são crimes orçamentários é altamente discutível". Disponível em: http://www.stf.jus.br/portal/constituicao/artigobd.asp? 
tem levado às ruas grande número de pessoas em manifestações e protestos organizadas pelos dois lados.

Neste contexto a RBPAE, coerentemente com a sua histórica defesa do Estado democrático de direito, posiciona-se em favor da legitimidade dos votos que elegeram a presidente Dilma Rousseff, reafirma o respeito à Constituição de 1988 e considera que qualquer tentativa de destituição de uma presidente eleita sem que tenha havido crime de responsabilidade constitui uma grave ameaça ao Estado republicano e, consequentemente, aos direitos dos cidadãos.

Desde o início desse embate político, a Anpae tem emitido ou assinado notas públicas em Defesa da Democracia, do Respeito ao Estado de Direito e do estrito cumprimento à Constituição Federal, conforme publicações em seu Portal. Assim, qualquer ensaio de ruptura da ordem democrática terá o repúdio desta instituição que não compactua com tentativas de redução de mandato de presidentes ou qualquer outro governante legitimamente eleito pela sociedade civil, senão em conformidade com a Constituição brasileira.

Em meio a esse cenário de apreensão e forte tensão social, lançamos um dossiê temático que aborda, predominantemente, estudos e pesquisas sobre planejamento educacional. Para introduzi-lo traçaremos um breve histórico das políticas de planos educacionais no Brasil, e, em seguida, passaremos à apresentação dos autores e artigos que comporão este número.

A ideia de que seria necessário pensar a educação brasileira de maneira organizada e sistemática tem início, no Brasil, com o Movimento dos Pioneiros da Educação Nova, na segunda década do século XX, "quando iniciou a implantação do processo de modernização conservadora da sociedade brasileira, no contexto da afirmação do processo de industrialização" (AZEVEDO, 2014, p. 267). Segundo essa autora, esse movimento tinha à frente um grupo de "intelectuais progressistas em relação à ordem oligárquica predominante e propugnava o estabelecimento no país de uma educação republicana, de massa, laica, obrigatória e gratuita, pautada em princípios científicos e pelos valores democráticos" (Idem p. 268).

Assim, o Manifesto dos Pioneiros da Educação Nova, lançado em 1932 é considerado um marco no sentido de estimular o repensar da educação brasileira segundo os princípios democráticos e republicanos, de modo a romper com a lógica até então vigente marcada pelo clientelismo patrimonialista. A Constituição de 1934 repercutiu essas ideias e, em seu artigo 150, determinou que fosse competência da União a fixação do "plano nacional de educação, compreensivo do ensino de todos os graus e ramos, comuns e especializados" (BRASIL.CF, 
1934). Entretanto esse processo foi interrompido pela ditadura Vargas (19371945), o que acabou por inviabilizar a implantação do plano (ANDREOTTI, 2006).

Do Manifesto dos Pioneiros até os dias atuais muitos marcos legais reafirmaram a necessidade de planejar a educação no Brasil. Com a Lei de Diretrizes e Bases da Educação Nacional (LDB - Lei $n^{\circ}$ 4.024) promulgada em 1961, foi elaborado o Plano Nacional de Educação de 1962, propondo um conjunto de metas a serem alcançadas em oito anos que previam a construção de uma educação republicana. Uma vez mais o plano ficou apenas no papel, interrompido pelo golpe militar (1964-1985). Dessa vez, segundo Azevedo (2014),

\footnotetext{
no projeto de desenvolvimento para a sociedade brasileira que o regime autoritário procurou implantar, o planejamento ganhou dimensão especial. Nos dois primeiros governos militares, a educação, a exemplo de outras políticas setoriais, foi planejada nos documentos norteadores da política econômica e a filosofia de ação adotada passou a privilegiar a aproximação entre os sistemas de ensino e o sistema econômico. Era a adoção do enfoque econômico da educação vinculada à teoria do capital humano. (p. 269)
}

Com o predomínio da abordagem econômica da educação no planejamento educacional, a política educacional passou a ser considerada como "um instrumento de melhoria dos recursos humanos para o desenvolvimento" (HORTA, 1982, p. 137). Durante a vigência do regime militar foram editados vários programas e planos nacionais que "visavam tornar a população brasileira tanto um fator de produção, pelos efeitos da escolarização sobre a produtividade de recursos, quanto destinatária dos resultados de progresso" (BRASIL, MEC, 1971, p. 24).

Com o fim do regime militar e a redemocratização, a partir de 1985, o Brasil passou a viver um período de transição democrática. Uma Assembleia Nacional Constituinte elaborou e promulgou a Constituição de 1988, que colocou as questões educacionais como direito social, o nível obrigatório de escolaridade como direito subjetivo, a gestão democrática como princípio e o planejamento educacional voltou a ser garantido. $\mathrm{Na}$ década seguinte foi promulgada a Lei 9.394/96, de Diretrizes e Bases da Educação Nacional, que, em atendimento à nova Constituição, definiu como da União a responsabilidade de elaboração do Plano Nacional de Educação, em regime de colaboração com os demais entes federados. De acordo com Azevedo (op. cit.), "o processo de construção do primeiro plano, pós-ditadura militar, refletiria tensões e contradições presentes na sociedade brasileira, mas permitiu um amplo debate sobre soluções para as questões educacionais, possível apenas em uma democracia política” (p. 271). 
Neste contexto, o Plano Nacional de Educação (PNE 2001-2010) veio à tona após três anos de tramitação, em meio a muitas disputas, tensões e contradições que refletiam a sociedade brasileira daquele período (AZEVEDO, 2014), mas importa aqui, considerando os limites deste editorial, ressaltar que o mérito deste plano está muito mais na sua capacidade de promover a mobilização e o debate em torno das pautas históricas de lutas dos trabalhadores da educação do que pela sua efetivação enquanto indutor de mudanças efetivas na educação brasileira. Os vetos do executivo às metas que demandavam o aumento de recursos do fundo público para sua implantação acabaram por torná-lo "letra morta" para grande parte das metas previstas.

É importante destacar que em 2003, com a eleição do presidente Lula, marcada por influência democrático-popular, houve mudanças importantes na conjuntura política do país que se fizeram sentir com a implementação de novos marcos regulatórios que visavam a elevar a qualidade da educação pública e, nesse contexto, foram retomadas algumas propostas presentes no Plano Nacional de Educação enviado pela sociedade Civil ao Congresso Nacional em 1998, substituído à época pelo Plano formulado pelo poder executivo. Dentre essas ações destacam-se a discussão e implementação do Plano de Desenvolvimento da Educação (PDE) e o Plano de Ações Articuladas (PAR), ausentes no PNE 2001-2010, mas que, ao serem trazidos à tona, reforçaram a articulação das políticas entre a união e os demais entes federados na implantação de inúmeros programas e projetos para a Educação Básica.

Em 2010, ocorreu a Conferência Nacional de Educação (CONAE), constituída como espaço democrático e aberto para que todos pudessem participar do desenvolvimento da Educação Nacional. Essa conferência foi intitulada "Construindo um Sistema Nacional Articulado de Educação: Plano Nacional de Educação, suas Diretrizes e Estratégias de Ação”. Como decorrência da CONAE, o governo federal elaborou e encaminhou ao Congresso Nacional o PL n. 8.035/2010, que tratava do Plano Nacional de Educação. De acordo com Azevedo (2014), "é no contexto destas orientações de políticas sociais que o PNE (2014-2024) foi concebido, emanado e aprovado, trazendo marcas não só das iniciativas progressistas, como também de corte conservador que continuaram presentes na ação governamental” (p. 273). Assim, o Planejamento Educacional brasileiro e seus desdobramentos políticos, que se materializam no cotidiano das redes e das escolas públicas em todo território nacional são marcados por grandes avanços e muitas contradições, como evidenciam as metas e estratégias do PNE 2014-2024. Além disso, a crise política e econômica tem acentuado as dificuldades para a implementação do Plano, sobretudo em razão dos cortes orçamentários, o que pode tornar inviável o cumprimento da meta 20, que prevê 
“ampliar o investimento público em educação pública de forma a atingir, no mínimo, o patamar de 7\% (sete por cento) do Produto Interno Bruto (PIB) do País no 5o (quinto) ano de vigência desta Lei e, no mínimo, o equivalente a 10\% (dez por cento) do PIB ao final do decênio".

Tendo em vista os embates, as rupturas e as (des) continuidades históricas nesse campo, é com grande satisfação que apresentamos a nossos leitores um número especial da RBPAE, com artigos que abordam as diversas dimensões teóricas e práticas das políticas de Planejamento Educacional, organizado em duas partes.

$\mathrm{Na}$ primeira parte estão os artigos organizados por docentes de três universidades federais: a professora Alda Maria Duarte Araújo Castro da UFRN, o professor Marcelo Soares Pereira da Silva da UFU e a professora Vera Lúcia Jacob Chaves da UFPA, que são resultados de pesquisas realizadas no âmbito de um Projeto financiado pelo Observatório da Educação/CAPES, intitulado Avaliação do Plano de Ações Articuladas (PAR): um estudo em municípios dos Estados do Rio Grande do Norte, Pará e Minas Gerais no período de 2007 a 2011. Este projeto teve como objetivo analisar a implantação do PAR no contexto das atuais políticas educacionais pressupondo que o desenvolvimento dessas políticas é conduzido em determinado momento histórico e respondem ao ritmo e à direção impressos pelo reordenamento do sistema capitalista. A pesquisa avaliou as repercussões do PAR nos sistemas educacionais dos municípios da amostra, analisando também as configurações das relações intergovernamentais entre os entes federados, objetivando evidenciar as mudanças ocorridas nos indicadores educacionais dos municípios dos estados envolvidos na pesquisa, considerando as quatro dimensões previstas no PAR. Na segunda parte, estão os demais artigos de demanda livre, que abordam o planejamento educacional e outros temas.

Na seção "Documentos" deste número, apresentada por Daniela da Costa Britto Pereira Lima, publicamos duas Resoluções homologadas pelo Conselho Nacional de Educação (CNE), por se constituírem marco muito importante no delineamento dos currículos dos cursos de formação de professores no Brasil. A primeira é a Resolução $n^{\circ} 2$, de $1^{\circ}$ de julho de 2015, que define as Diretrizes Curriculares Nacionais para a formação inicial em nível superior (cursos de licenciatura, cursos de formação pedagógica para graduados e cursos de segunda licenciatura) e para formação continuada. Em seguida, apresentamos a Resolução $\mathrm{n}^{\mathrm{o}}$ 1, de 11 de março de 2016, que estabelece as Diretrizes e Normas Nacionais para a Oferta de Programas e Cursos de Educação Superior na Modalidade a Distância.

Abrindo a primeira parte apresentamos o artigo de Lúcia de Fátima Valente, Maria Simone Costa e Fernando Henrique dos Santos intitulado Nas 
trilhas do planejamento educacional e seus contornos nas políticas de educação no Brasil, que, por meio de uma pesquisa bibliográfica apresenta e analisa as políticas de planejamento educacional no Brasil entre 1934 e 2014, apreendendo as manifestações sociopolíticas e culturais neste período, em uma síntese histórica bem tecida e bem fundamentada.

Em seguida está o texto de autoria de Antônio Cabral Neto, Alda Maria Duarte Araujo Castro e Luciane Terra dos Santos Garcia, intitulado Plano Municipal de Educação: elaboração, acompanbamento e avaliação no contexto do PAR, que apresenta o papel dos Planos Municipais de Educação (PME) na organização do Sistema Nacional de Educação (SNE). Utilizando-se de análise documental e uma abrangente revisão de literatura, o estudo analisa o Plano de Ações Articuladas (PAR) em municípios norte-rio-grandenses, na dimensão da gestão educacional.

O Plano de Desenvolvimento da Educação (PDE) no contexto do novo desenvolvimento brasileiro é o título do artigo de Cecília Carolina Simeão de Freitas e Marcelo Soares Pereira dos Santos, que, por meio de uma revisão de literatura e cuidadosa análise dos documentos que orientam o PDE, apresenta a perspectiva do novo desenvolvimentismo que balizou as políticas públicas implementadas no Brasil no período de 2003 a 2010, ao mesmo tempo em que situou o Plano de Desenvolvimento da Educação (PDE) e o planejamento educacional nesse contexto.

O PAR e a formação dos professores é o tema dos próximos artigos. O primeiro, de Arlete Maria Monte de Camargo, Maria Edilene Silva Ribeiro e Odete da Cruz Mendes, intitulado Implicações do Plano de Ações Articuladas na formação docente e desempenho escolar - o caso do Pará apresenta, por meio de uma análise de dados, extraídos da base de dados do Inep/MEC, de cinco municípios do Pará, como se dá a relação entre as políticas para formação continuada de professores no Plano de Ações Articuladas (PAR) no período de 2007 a 2011 e a melhoria dos indicadores educacionais.

Os autores Francisca Adilma Braga Soares Aureliano e Maria Aparecida de Queiroz também se debruçaram sobre o tema da formação de professores no contexto do PAR, no artigo intitulado O planejamento e as relações federativas no Plano de Açôes Articuladas: assimetrias nas ações de formação de professores. O estudo evidencia algumas dimensões do federalismo e suas implicações na educação brasileira, nas relações federativas e no planejamento educacional no que diz respeito ao Plano de Ações Articuladas (PAR 2007-2011). Quanto às ações de formação de professores esta política minimizou o favorecimento político, característico das relações históricas dos dirigentes locais com o Ministério de Educação e promoveu também mecanismos de regulação do Estado, limitando a autonomia do município na implementação das ações. 
O texto seguinte, escrito por Gilmar Barbosa Guedes e Maria Goretti Cabral Barbalho, intitulado Planejamento educacional e gestão democrática: dimensões política e instrumental no PAR apresenta uma análise das vertentes do planejamento educacional na gestão democrática, por meio da análise de dados relativos ao PAR nos municípios de Acari, Natal, Mossoró, Riachuelo e São José de Campestre, do estado do Rio Grande do Norte. Os estudos revelaram que os municípios tendem a assumir a gestão com características dos modelos gerencial, democrático-participativo ou uma síntese dos dois, a depender dos interesses econômicos, das condições geopolíticas e a cultura organizacional do contexto.

O estudo que fecha a primeira parte deste dossiê tem como autores Dalva Valente Gutierres e Rosana Gemaque Rolim e intitula-se O Financiamento da educação a partir do Plano de Ações Articuladas (PAR) em municípios paraenses: regime de colaboração? O estudo analisa o financiamento da educação no contexto do PAR nos municípios de Altamira, Barcarena, Belém, Cametá e Castanhal, de 2010 a 2014, com o objetivo de dimensionar a responsabilidade dos entes federativos na efetivação do regime de colaboração, marcado por uma densa fundamentação e uma análise pertinente do objeto de estudo.

Abrindo a segunda parte deste dossiê apresentamos outros três estudos que também abordam o Planejamento Educacional em diversos aspectos e dimensões. Iniciamos com o texto intitulado Estudo comparativo exploratório dos Planos Nacionais de Educação no Brasil e na Colômbia, de autoria de Diana Marcela Cuervo Escobar e Alicia Bonamino, que procurou compreender o planejamento educacional público a partir da comparação dos documentos dos Planos Nacionais de Educação do Brasil e da Colômbia. As principais conclusões mostram que os planos têm uma origem político-social similar, compartilham o vínculo com uma agenda mundial para o planejamento educativo e apresentam uma série de tensões entre os fins da educação e os meios para atingi-los.

Relacionando o planejamento aos aspectos burocráticos que caracterizam as escolas, o artigo de Miguel Henrique Russo intitulado "planejamento e burocracia na prática escolar: sentidos que assumem na escola pública" apresenta o relato extraído de uma pesquisa empírica e de alguns pressupostos sobre a prática do planejamento no âmbito escolar revelando uma prática de planejamento repetitiva e espontânea. O texto contribui para orientar a prática escolar segundo uma perspectiva na qual o planejamento seja um instrumento metodológico de construção do projeto escolar de modo a assumir um papel de catalisador da reflexão coletiva na escola.

No estudo de Andreia Couto Ribeiro e Wellington Ferreira de Jesus intitulado O Plano de Ações Articuladas para a Educação Básica (PAR): elementos para a construção da assistência técnica e financeira da união aos estados e municípios brasileiros, à luz de uma pertinente fundamentação teórica, os autores analisam os dados sobre o 
financiamento, buscando verificar os critérios que são utilizados para a efetivação da assistência técnica e financeira da União, bem como identificar os avanços que o PAR propiciou na implantação e monitoramento dos investimentos na Educação Básica.

O próximo artigo intitula-se $A$ Educaşão Especial no âmbito do planejamento orçamentário do município de Vitória - Espirito Santo, escrito por Marileide Gonçalves França, analisa a ação do Poder Público no provimento de recursos à Educação Especial no âmbito do planejamento orçamentário do município de Vitória, Espírito Santo, no período de 2008 a 2013 e conclui que, mesmo integrando o orçamento municipal, os valores previstos para essa modalidade educacional estavam subdimensionados e/ou agregados às outras etapas de ensino.

Em seguida, Jair Jonko Araújo e Álvaro Moreira Hypolito assinam o artigo Novos significados para Educação Profissional e Tecnológica no Instituto Federal Sul-rio-grandense: a política de criação dos Institutos, no qual discutem os significados induzidos pela política oficial de criação dos Institutos Federais, seu acolhimento na documentação institucional e a produção de sentidos pelos gestores. Concluise que existe um mito de ensino consolidado na rede federal e que não há ainda políticas institucionais hegemônicas para pesquisa e extensão.

Encerrando a seção de artigos apresentamos o texto de Nancy Nonato de Lima Alves intitulado Educação da infância: o lugar da participação da família na instituição educativa, no qual a autora aborda a participação familiar como dimensão da gestão democrática na Educação Infantil, identifica contradições e desafios da participação da família nessa etapa educacional e conclui que a democratização da gestão requer superar a participação restrita e operacional, de modo que se construa um amplo envolvimento familiar nas decisões e ações políticas e pedagógicas da instituição de Educação Infantil.

Neste primeiro número de 2016, abrimos a revista apresentando uma homenagem da RBPAE à saudosa professora Regina Vinhais Gracindo, e expresidente da ANPAE (1996-2000), escrita pela professora Márcia Ângela Silva Aguiar, também ex-presidente da ANPAE (biênios 2011-2013 e 2013-2015).

Desejamos a todos e todas uma ótima leitura.

Lúcia Maria de Assis

Editora

Daniela da Costa Britto Pereira Lima

Editora Associada 


\section{REFERÊNCIAS}

ANDREOTTI, Azilde Lina. A administração escolar na era Vargas e no nacional desenvolvimentismo (1930 - 1964). Revista HISTEDBR On-line. Campinas/SP, $\mathrm{n}^{\circ}$ especial, p.102-123, ago. 2006. Disponível em: http://www.histedbr.fe.unicamp. br/revista/edicoes/22e/art8_22e.pdf. Consulta em: 29/04/2016.

AZEVEDO, Janete Maria Lins de. Plano Nacional de Educação e planejamento. A questão da qualidade da educação. Revista Retratos da Escola, v. 8, nº 15, p. $265-$ 280, jul./dez. 2014.

BRASIL. Lei $\mathrm{n}^{\circ}$ 13.005, de 25 de junho de 2014. Aprova o Plano Nacional de Educação e dá outras providências. Diário Oficial da União, Brasilia, DF, 26 jun. 2014.

BRASIL. Lei $\mathrm{n}^{\circ}$ 10.172, de 9 de janeiro de 2001. Aprova o Plano Nacional de Educação e dá outras providências. Diário Oficial da União, Brasília, DF, 10 jan. 2001.

BRASIL. Lei $n^{\circ} 9.394$, de 20 de dezembro de 1996. Estabelece as diretrizes e bases da educação nacional. Diário Oficial da União, Brasília, DF, 1996.

BRASIL, Ministério da Educação. Plano setorial de educação e cultura, 1972/1974. Brasilia, DF: MEC, 1971.

BRASIL. Lei $\mathrm{n}^{\circ}$ 4.024, de 20 de dezembro de 1961. Fixa as diretrizes e bases da educação nacional. Diário Oficial da União, Brasilia, DF, 1961.

BRASIL. Constituição da República dos Estados Unidos do Brasil. Constituição (1934). Rio de Janeiro: Assembleia Nacional Constituinte, 1934.

HORTA, José Silvério B. Liberalismo, tecnocracia e planejamento educacional no Brasil. São Paulo: Cortez; Autores Associados, 1982. 